\title{
Retraction Note to: A robust vector field correction method via a mixture statistical model of PIV signal
}

\author{
Yong Lee $^{1} \cdot$ Hua Yang ${ }^{1}$ Zhouping Yin ${ }^{1}$
}

Published online: 23 June 2016

(C) Springer-Verlag Berlin Heidelberg 2016

\section{Retraction Note to: Exp Fluids (2016) 57:31 \\ DOI 10.1007/s00348-016-2115-y}

This article has been retracted by the Editors-in-Chief of the journal on the authors' initiative. The reasons for the retraction are a technical mistake by the authors and substantial overlap of text with the previous publications Ma J, Zhao J, Tian J, Yuille AL, Tu Z (2014) Robust point matching via vector field consensus. IEEE Trans Image Process 23(4):1706-1721 and Garcia D (2011) A fast all-in-one method for automated post-processing of PIV data. Exp Fluids 50(5):1247-1259.

The online version of the original article can be found under doi:10.1007/s00348-016-2115-y.

Hua Yang

huayang@hust.edu.cn

1 State Key Laboratory of Digital Manufacturing Equipment and Technology, Huazhong University of Science and Technology, Wuhan 430074, China 